Research Article

\title{
CFD Analysis of the Primary Cooling System for the Small Modular Natural Circulation Lead Cooled Fast Reactor SNRLFR-100
}

\author{
Pengcheng Zhao, Kangli Shi, Shuzhou Li, Jingchao Feng, and Hongli Chen \\ School of Nuclear Science and Technology, University of Science and Technology of China, Hefei, Anhui 230027, China
}

Correspondence should be addressed to Hongli Chen; hlchen1@ustc.edu.cn

Received 10 August 2015; Revised 11 December 2015; Accepted 16 December 2015

Academic Editor: Stephen M. Bajorek

Copyright (C) 2016 Pengcheng Zhao et al. This is an open access article distributed under the Creative Commons Attribution License, which permits unrestricted use, distribution, and reproduction in any medium, provided the original work is properly cited.

Small modular reactor (SMR) has drawn wide attention in the past decades, and Lead cooled fast reactor (LFR) is one of the most promising advanced reactors which are able to meet the safety economic goals of Gen-IV nuclear energy systems. A small modular natural circulation lead cooled fast reactor-100 MWth (SNRLFR-100) is being developed by University of Science and Technology of China (USTC). In the present work, a 3D CFD model, primary heat exchanger model, fuel pin model, and point kinetic model were established based on some reasonable simplifications and assumptions, the steady-state natural circulation characteristics of SNCLFR-100 primary cooling system were discussed and illustrated, and some reasonable suggestions were proposed for the reactor's thermal-hydraulic and structural design. Moreover, in order to have a first evaluation of the system behavior in accident conditions, an unprotected loss of heat sink (ULOHS) transient simulation at beginning of the reactor cycle (BOC) has been analyzed and discussed based on the steady-state simulation results. The key temperatures of the reactor core are all under the safety limits at transient state; the reactor has excellent thermal-hydraulic performance.

\section{Introduction}

Among the next generation of nuclear reactors, the lead fast reactor (LFR) is one of the most promising advanced reactors which are able to meet the safety goals of Gen-IV nuclear energy systems. The LFR system features chemical inertness with air and water, high boiling point, and a closed fuel cycle for efficient conversion of fertile uranium and management of actinides [1]. Recently, research about small modular reactor (SMR) has rapidly increased, which has been recognized as innovative production for niche markets due to the fact that they can be used for multipurpose applications of desalination, district heating, ship propulsion, and small scale power generation $[2,3]$. Owing to lead's and lead-bismuth's outstanding natural circulation performance, LFR systems have excellent natural circulation ability, which will improve the reactor passive safety features significantly [4]. Several small modular natural circulation LFR systems have been developed in the world. In the United States, several natural circulation lead-cooled fast reactors were developed by the Argonne National Laboratory (ANL), such as SSTAR and SUPERSTAR $[5,6]$. In Europe, a natural circulation LFR had been selected as the subcritical reactor for an Accelerator Driven Systems (ADS), namely, Energy Amplifier (EA) [7]. In Korea, a SMR named URANUS which applied a passive cooling feature to both normal and abnormal operations is being developed by Seoul National University; the reactor has a refueling interval of 20 years without assembly reconfiguration and the rated thermal power is $100 \mathrm{MW}$, which is well suited as a distributed power source [8]. In China, a $10 \mathrm{MW}$ lead-alloy cooled reactor named CLEAR-I has been developed under the support of the Chinese ADS project [9-11]; meanwhile, a small modular natural circulation lead cooled fast reactor-100 MWth (SNRLFR-100) is being developed by USTC, which has multiple industrial applications, such as generating electricity and supplying heating.

Thermal-hydraulics is recognized as a key scientific subject in the development of LFR [12]. Compared with the traditional reactors that utilize mechanical pumps, the small 
modular natural circulation LFRs have many outstanding advantages, while the thermal-hydraulics of the typical LFR primary cooling system is a coupling problem of the reactor core power, the operation condition of the secondary cooling system, the primary circuit layout, and so forth. This will lead to different micro- and macroscopic flow and heat transfer behaviors occurring in the natural circulation LFR primary cooling system [12]. Accurately predicting the coolant thermal-hydraulic characteristics of LFR primary circuit will not only do much good for evaluating the thermal-hydraulic performance of whole reactor cooling system but also provide the basis for optimization design of primary cooling system's key components through a more accurate assessment of the coolant temperature, velocity, and pressure distributions. The traditional method based on the one-dimensional lumpedparameter method such as RELAP or TRACE is unsuitable to simulate multidimensional thermal-hydraulic phenomena [13]. The application of CFD codes to study the multidimensional thermal-hydraulic phenomena in the reactor system can increase the accuracy of analysis result and help people better understand the real physical phenomena in the reactor system [12]. Many LFR primary cooling system thermalhydraulic characteristics analyses have been carried out in some universities and nuclear research organizations $[10,14$, 15].

The aim of this paper is to study the passive behavior of a typical small modular LFR named SNRLFR-100, of which main cooling mechanism is natural circulation. For that purpose, a 3D model of that LFR primary cooling system has been established using the computational fluid dynamic (CFD) FLUENT code by taking advantage of the reactor symmetry; the 3D CFD model covers a $90^{\circ}$ part of the vessel including 1 of 4 primary circuits with all their components. As it is impossible to run a CFD model that is able to simulate the whole primary cooling system of the SNRLFR-100 in detail currently, several auxiliary models were developed, such as the core model, the primary heat exchanger (PHX) model, the fuel rod model, and the point kinetic model. Based on the CFD model of the primary loops with all their components, an analysis of the steady state operation mode was performed and the key thermal-hydraulic phenomena were illustrated and discussed. In addition, an unprotected loss heat sink (ULOHS) transient simulation at BOC was conducted in order to have a first evaluation of the system safety features in accident conditions; the simulation results show that the SNRLFR-100 has excellent inherent safety performance.

\section{SNRLFR-100 Design Description}

A schematic vertical section of SNRLFR-100 primary cooling system is shown in Figure 1. The design objective of SNRLFR100 is to develop a natural circulation LFR based on the stateof-the-art construction technology, which can be served as a small modular natural circulation LFR research platform and a distributed power source. The rated thermal power of SNRLFR-100 is $100 \mathrm{MW}$ and the refueling interval is 10 years without assembly reconfiguration. This reactor is a typical pool type fast reactor with an array of heterogeneous square fuel assemblies. The reactor core, the primary heat

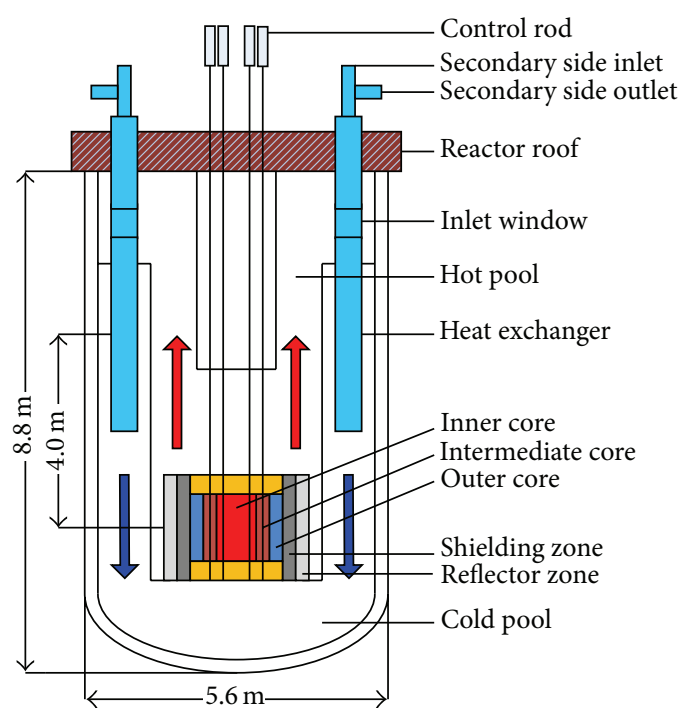

FIGURE 1: SNRLFR-100 vertical section scheme.

exchangers, and other important components of the primary circuit are immersed inside a large pool of lead. The lead pool and the reactor primary components are all housed in the main vessel. The lead pool is bifurcated into two regions by the heat barrier, namely, hot pool and cold pool. The primary coolant is driven by natural circulation by making full use of lead's large thermal expansion coefficient and low kinetic viscosity properties. During normal operation of the reactor, driving by the natural circulation force, the liquid lead flows through the core assemblies and removes the heat generated in them before entering the hot pool. From the hot pool, the liquid lead flows through 4 tube-in-shell kidney-shaped primary heat exchangers, where it exchanges heat with the secondary coolant and back into the cold pool. The main parameters of SNRLFR-100 are given in Table 1.

\section{Calculation Model Description}

Figure 2 shows the core layout of SNRLFR-100. The 3D CFD model of SNRLFR-100 primary cooling system is established by taking advantage of the reactor system, which covers a $90^{\circ}$ part of the main vessel and all its components with a polyhedral mesh of about 6 million cells. On account of the primary circuit layout has great influence in the establishment of natural circulation of the primary cooling system, and taking into account the fact that it is impossible to run a CFD model which is able to simulate the detail geometry design of the primary cooling system, several individual CFD models were developed based on some reasonable simplifications and assumptions. The effects of the secondary cooling system are considered by a one-dimensional model using a user subroutine coupled with the 3D model of the primary circuit with the heat transfer in the PHX as a boundary condition. The core, hot pool, cold pool, and primary side of PHX are modeled as an integrated CFD model, without any external coupling. Meanwhile, in order to have a preliminary analysis of the reactor safety performance, some key thermal-hydraulic 
TABLE 1: Main design parameters of SNCLFR-100.

\begin{tabular}{lc}
\hline Design parameters & Values or characteristics \\
\hline Thermal power (MWt) & 100 \\
Fission fuel & MOX \\
Refueling interval (years) & 10 \\
Plant design lifetime (years) & 30 \\
Primary coolant & Lead \\
Primary heat transport system & Compact pool type \\
Core configuration & Closed square array \\
Cladding & T91 \\
Primary normal cooling model & Fully natural circulation \\
Core inlet/outlet temperature & $400 / 480$ \\
$\left({ }^{\circ}\right.$ C) & 8528 \\
Core coolant flow (kg/s) & Water/steam forced \\
Secondary normal cooling model & circulation \\
Abnormal decay heat removal & Reactor vessel auxiliary \\
Secondary coolant mass flow & cooling system \\
(kg/s) & 18.0 \\
Secondary coolant inlet/outlet & Rankine cycle with \\
temperature $\left({ }^{\circ} \mathrm{C}\right)$ & superheated steam \\
Steam generators & 8.8 \\
Secondary water/steam cycle & 5.6 \\
Main vessel height (m) & shell-tube type \\
Main vessel diameter $(\mathrm{m})$ & \\
\hline
\end{tabular}

parameters such as the maximum fuel temperature and maximum cladding temperature need to be investigated; thus the fuel rod model and the point kinetic model were established and coupled with the 3D CFD model to evaluate the SNRLFR-100 safety features at nominal condition.

3.1. The Core Model. Owing to the fact that the SNCLFR-100 is cooled by natural circulation completely for both normal and abnormal conditions, in order to reduce pressure loss in the core region, large pitch-to-diameter was adopted to get wide path of coolant flow. The reactor core consists of three enrichment zones of fuel assemblies, the control rod assemblies, the reflector assemblies, and a surrounding shielding zone, shown in Figure 2. There are 204 fuel assemblies, 36 control assemblies, 48 reflector assemblies, and 84 shielding assemblies. The design parameters of SNCLFR-100 core are listed in Table 2.

The fuel assembly shown in Figure 3 is a $9 \times 9$ pins lattice, 81 pins per assembly. The pitch-to-diameter ratio is 1.426 and the assembly pitch is $160.0 \mathrm{~mm}$. The wide coolant paths between rods can reduce the pressure drop significantly and enhance the reactor natural circulation capability. The control assembly also adopts $9 \times 9$ square pin lattice, 72 pins per assembly, where the center beam box is used to hold the control rod. The scheme of control assembly is shown in Figure 4 . To overcome problems brought by significant buoyancy
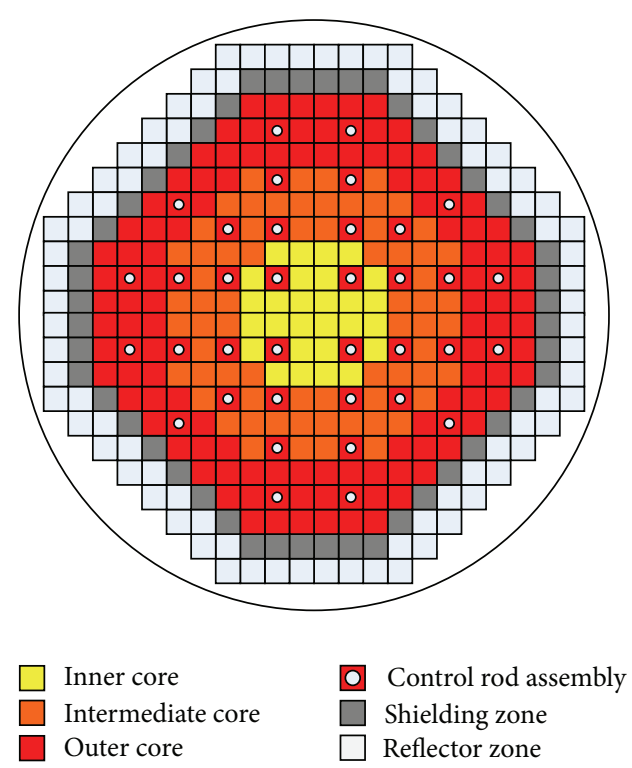

FigURE 2: SNCLFR-100 core layout.

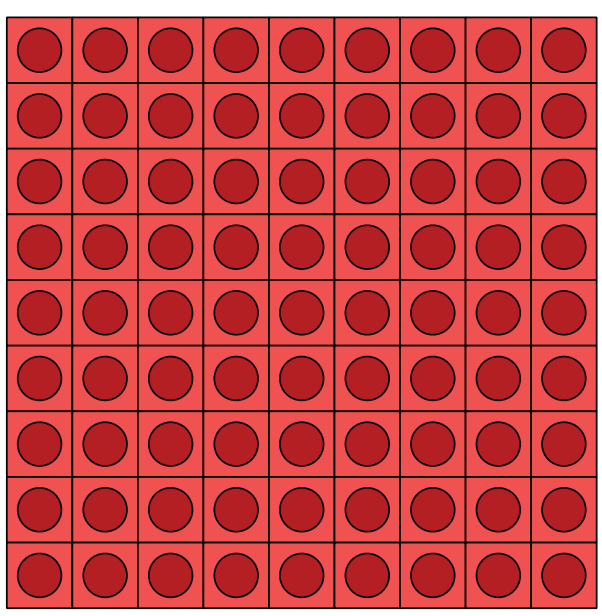

Figure 3: Scheme of fuel assembly.

effects in liquid lead of high density, additional weight schemes, for example, using heavy metal tungsten material, need to be considered during mechanical design of fuel assembly and control assembly.

In the present CFD model, the core is divided into five radial zones and each zone is represented as a ring in the core location, namely, the inner fuel ring, the middle fuel ring, the outer fuel ring, the shielding ring, and the reflector ring. The cross section area of each ring is equal to the total cross section area of all the fuel assemblies and control rod assemblies that located in this ring. The core power generated by SNRLFR-100 is $100 \mathrm{MWt}$. The BOC conditions are considered for the present work. The heat generated in the core is defined as ring dependent with a uniform heat source in the active fuel region. The power generated by the shielding ring and reflector ring is very small and is not taken into consideration in the core model. A 3D core model can be established 
TABLE 2: Design parameters of SNCLFR-100 core.

\begin{tabular}{lc}
\hline Design parameters & Values or characteristics \\
\hline Number of fuel assemblies & 204 \\
Number of control assemblies & 36 \\
Number of pins per one fuel assembly & 81 \\
Number of pins per one control assembly & 72 \\
Pin pitch-to-diameter ratio & 1.426 \\
Fuel pin pitch & $17.4(\mathrm{~mm})$ \\
Fuel pin diameter & $12.2(\mathrm{~mm})$ \\
Core height & $3400(\mathrm{~mm})$ \\
Active core height & $1000(\mathrm{~mm})$ \\
Equivalent core diameter & $3460(\mathrm{~mm})$ \\
Fuel compositions & \\
$\quad$ Layer 1 & \\
$\quad$ Layer 2 & $\mathrm{PuO}_{2}(16 \%)+\mathrm{UO}_{2}(84 \%)$ \\
$\quad$ Layer 3 & $\mathrm{PuO}_{2}(19 \%)+\mathrm{UO}_{2}(81 \%)$ \\
Fuel pellet diameter & $\mathrm{PuO}_{2}(24 \%)+\mathrm{UO}_{2}(76 \%)$ \\
Cladding outer diameter & $9.8\left(\mathrm{~mm}^{2}\right)$ \\
Fission gas plenum height & $12.2(\mathrm{~mm})$ \\
\hline
\end{tabular}

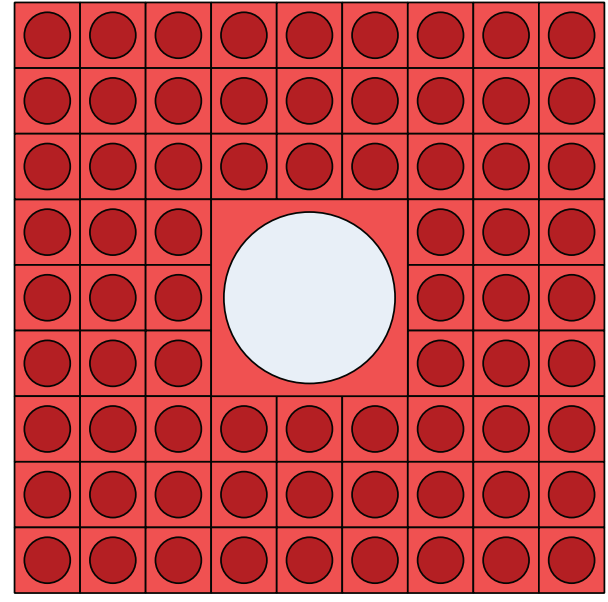

FIGURE 4: Scheme of control rod assembly.

based on those simplifications. Figure 5 shows the scheme of simplified core model. The volumetric heat source of the core is ring dependent with an axial power distribution given in Figure 6.

Limited by the current computational capability, it is impossible to simulate the detail geometrical design of each assembly; the pressure losses have to be implemented using porous medium approach. The effect of the porous media on the flow was defined using lumped parameters $[16,17]$. The parameters are typically taken to be resistance coefficients for a source term in the momentum equation. The inertial and viscous coefficients are required for the porous media in the momentum equation. This term is in the form of:

$$
S_{i}=-D_{i} \mu(T) v_{i}-C_{i} \frac{1}{2} \rho(T)|\vec{V}| v_{i},
$$

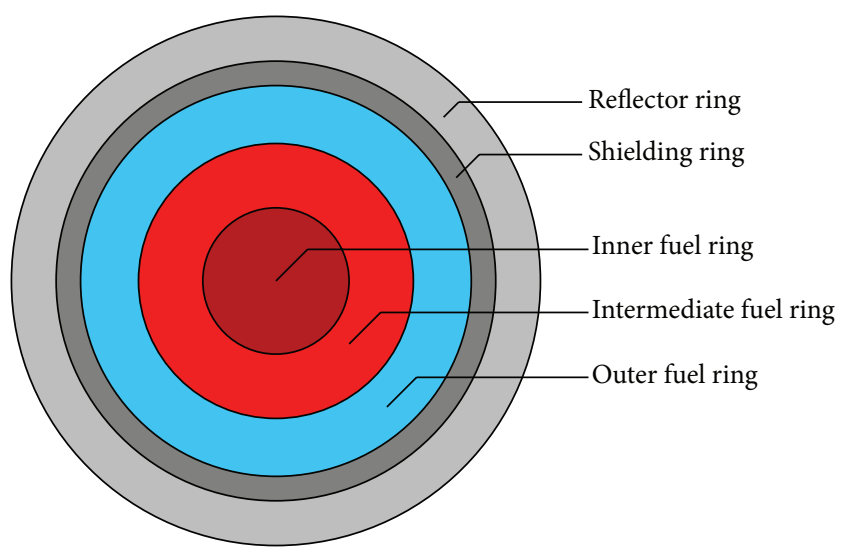

FIGURE 5: The simplified CFD model of SNRLFR-100 core.

where $v_{i}$ refers to the model geometry inlet velocity. $\mu(T)$ and $\rho(T)$ refer to the temperature dependent dynamic viscosity and density of the coolant. $D_{i}$ and $C_{i}$ represent the viscos and inertial pressure loss coefficient, respectively. The advantage of this approach is the possibility of creating a temperature dependent pressure loss relation [14]. A curve fit of $\Delta P / L$ versus $v_{i}{ }^{2}$ and $v_{i}$ can be determined using the following equation (ANSYS Incorporated, 2011):

$$
\frac{\Delta P_{\text {porous }}}{L}=-S_{i}=-\left(C_{i} \frac{1}{2} \rho(T)\left|v_{i}\right|+D_{i} \mu(T)\right) v_{i} .
$$

Pressure loss coefficients based on the work of Rehme [18] are implemented, which take into account the losses at the inlet and outlet of the core, the losses by the flow through the subchannels, and 6 spacers. Based on the experiment dates or the system code calculation results, we can get the relationship between the pressure drop and velocity of the core, 


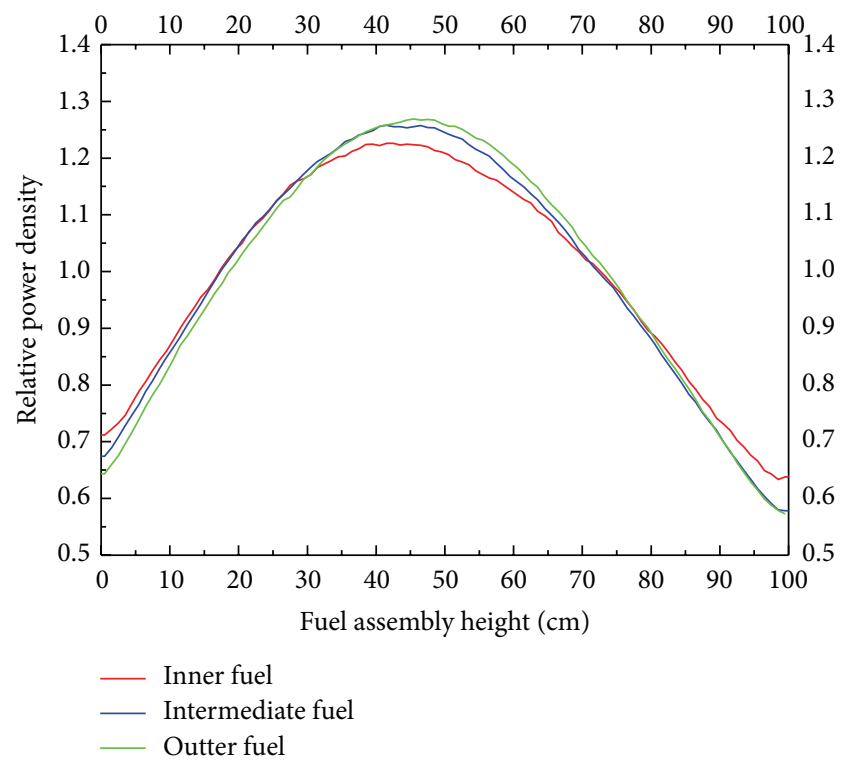

FIgURe 6: Assembly axial power distribution.

and the following equation can be easily yielded by fitting the pressure drop and the velocity formula:

$$
\Delta P_{\text {porous }}=a * v^{2}+b * v,
$$

where $\Delta P_{\text {porous }}$ is the total pressure drop of the porous media, $v$ is the coolant velocity through the core, and $a$ and $b$ are the coefficient of the fitted equation. Relating the pressure drop to the source term can be expressed as

$$
\Delta P_{\text {porous }}=-S_{i} L
$$

where $L$ is the thickness of the porous media. Solving the above equations and taking into account the detailed geometry, the viscous pressure loss coefficient $D_{i}$ and the inertial pressure loss coefficient $C_{i}$ of each ring of the core can be calculated easily (ANSYS Incorporated, 2011).

3.2. Fuel Rod Model. The simulation of the core introduced in the previous section takes into account average quantities over the rings and computes average coolant temperatures. When the coolant average temperatures are known, then temperature profiles inside the fuel rod and the cladding can be computed by using standard assumptions and standard heat transfer correlations. We mark that, in the liquid metal case and in three-dimensional configuration, the heat exchange coefficient may not be constant along the vertical coordinate and standard heat exchange models cannot be appropriate. The fuel rod model that we used in this work is presented in Figure 7. In this model we investigate the heat transfer model between the liquid metal coolant and the fuel rod with CFD code. From the core computations previously proposed, we were able to define only average ring temperatures. For temperatures inside the fuel rod, we can use the average ring

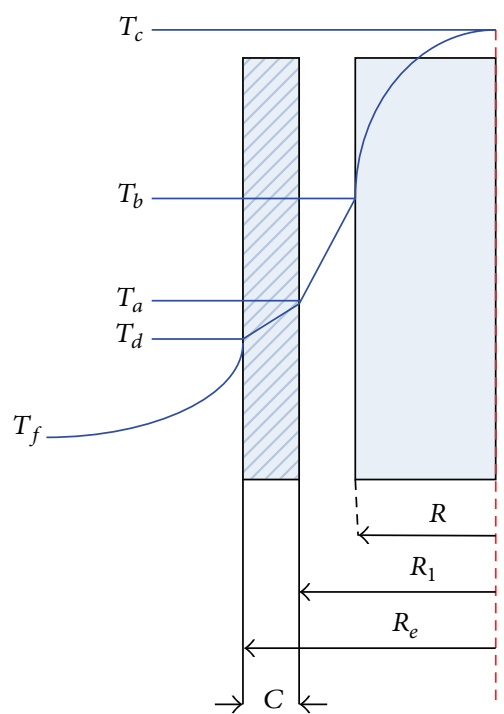

FIGURE 7: Temperature distribution in an assembly channel.

coolant temperature $T_{f}$ and standard analytical formulas. We assume that

$$
\begin{aligned}
T_{c}= & T_{f}+\Delta T_{1}+\Delta T_{2}+\Delta T_{3}+\Delta T_{4} \\
= & T_{f}+\left(T_{c}-T_{b}\right)+\left(T_{b}-T_{a}\right)+\left(T_{a}-T_{d}\right) \\
& +\left(T_{d}-T_{f}\right),
\end{aligned}
$$

where $T_{c}$ is the temperature on the fuel rod axis and $T_{d}$ is the cladding temperature. With the date from the open literature and experimental values, the temperature jump $\Delta T_{1}, \Delta T_{2}$, $\Delta T_{3}$, and $\Delta T_{4}$ can be computed. With the fuel rod model, the center temperature of the rod and max. temperature of the cladding for each fuel ring can be computed, which is the two most important values to access the thermal-hydraulic performance and safety characteristics of the reactor. Detailed fuel rod model description can refer to Chen et al. 2015 [13], which is developed by our research team.

3.3. The Primary Heat Exchanger Model. On account of the computational limitations, we cannot resolve the heat exchanging straight pipe structures. As consequence, the pressure drop of the PHX has to be implemented by volumetric source terms and the heat exchanger region is also simulated as porous medium model. Using the same method described in Section 3.1, we can get the pressure loss coefficients of primary heat easily. However, in order to keep the paper reasonably concise, detailed calculation process is not presented here.

The SNRLFR-10 contains 4 PHX units, and the average inlet and outlet primary coolant temperatures are $480^{\circ} \mathrm{C}$ and $400^{\circ} \mathrm{C}$, respectively. The PHX secondary system is cooled by water with a temperature of $T=340^{\circ} \mathrm{C}$ at the inlet and produces superheated steam at 18 bar and $430^{\circ} \mathrm{C}$. At nominal conditions each unit has to remove $25 \mathrm{MW}$ at a coolant flow rate of $18.0 \mathrm{~kg} / \mathrm{s}$. The conceptual design of the primary heat exchanger is shown in Figure 8. The pressurized water is 


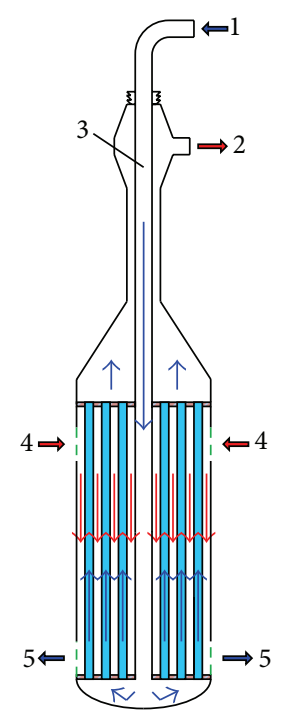
(1) Water inlet pipe
(2) Water outlet pipe
(4) Lead inlet window
(3) Center pipe
(5) Lead outlet window

Figure 8: Conceptual design of primary heat exchanger.

pumped into the primary heat exchanger where the water flows downward in the central pipe and then flows upward in tube side and absorbs heat from the primary coolant that flows downward in the shell side.

The PHX is modeled as porous media with distributed pressure drop in momentum equations and heat sink in energy equation. The formulation of the heat sink of the PHXs is the main interest for the model, as it is used for establishing the temperature level of the primary loops, which will directly affect the establishment of natural circulation in the primary circuit. A linear dependency of the heat flux based on two fixed temperatures at the PHX inlet and outlet is assumed. The total source heat reads

$$
Q_{\mathrm{SG}}= \begin{cases}-k\left(T-T_{\min }\right), & \overline{T_{\mathrm{SG}}}>T_{\min } \\ 0, & \overline{T_{\mathrm{SG}}}<T_{\min },\end{cases}
$$

where $k$ is given by $25 \mathrm{MW} / 135^{\circ} \mathrm{C}=0.1852 \mathrm{MW} /{ }^{\circ} \mathrm{C}$ and $\overline{T_{\mathrm{SG}}}$ is the average lead temperature at the SG inlet. In order to further simplify this model we may set $T_{\min }=345^{\circ} \mathrm{C}$ and assume that the PHX gives fixed temperature and mass flow rate at secondary side. If the coolant on the primary side has reached $345^{\circ} \mathrm{C}$, no heat is transferred anymore. The volumetric source term is implicated as

$$
-\mathrm{Q}=\frac{T_{\text {lead,in }}-345^{\circ} \mathrm{C}}{135^{\circ} \mathrm{C}} * 25 \mathrm{MW} / V_{\mathrm{PHX}},
$$

where $V_{\mathrm{PHX}}$ is the total volume of heat exchange region and $T_{\text {lead,in }}$ is the average coolant temperature at the inlet of PHX primary side.

3.4. Point Kinetic Model. The point kinetic model is a simple but useful mode for calculating reactor fission power; it is widely used in the traditional nuclear system analysis codes, such as RELAP5 and ATHLET. In the present work, the timedependent portion of the reactor fission power is calculated by solving the space-averaged and one-energy group reactor kinetics equation. For a fast reactor, the one-energy group assumption is reasonable. The mathematical equations of point kinetic model can be written as

$$
\begin{aligned}
& \frac{d N(t)}{d t}=\frac{\rho(t)-\beta}{\Lambda} N+\sum_{j=1}^{6} \lambda_{j} C_{j}(t), \\
& \frac{d C_{j}(t)}{d t}=\frac{\beta_{j}}{\Lambda} N(t)-\lambda_{j} C_{j}(t),
\end{aligned}
$$

$$
(j=1,2, \ldots, 6),
$$

where $\rho(t)$ is total reactivity; it contains two parts, that is, the external reactivity and the feedback reactivity. The external reactivity is caused by the insertion or withdrawal of control rods, which can be simulated as a time function, while the reactivity feedback is used to calculate the total reactivity considering the various mechanisms such as Doppler effect, core radial and axial expansions, coolant density effect, and coolant temperature variation.

Apart from the fission power, the reactor decay power should also be taken into consideration during the accidents process. For simplification, six groups of delayed neutrons are considered for the current model. For detailed description and solution process of point kinetic model the reader can refer to Chen et al. 2015 [13].

3.5. Control Plug. The refueling interval of SNRLFR-100 is 20 years without assembly reconfiguration, so we did not design the refueling machine on the reactor roof. The control rod guide tubes are sparsely distributed in the hot pool, which will not have great influence on the coolant mixing and flow. Hence, we did not consider the detail geometry design of control plug in the current CFD model.

3.6. Model Assumptions and Boundary Conditions. We considered that free surface instabilities of the lead can be neglected. Therefore, the top of the CFD model is treated as a simplified free-slip adiabatic wall; it was considered as a blackbody for radiation calculations with no thickness. As boundary condition, a heat flux derived from RVACS (Reactor Vessel Auxiliary Cooling System) CFD results is imposed on the outer main vessel wall; symmetrical zero-gradient boundary conditions are used in the circumferential direction. The RVACS of SNCLFR removes $0.7 \mathrm{MW}$ when the vessel wall temperature is $400^{\circ} \mathrm{C}$ and $1.2 \mathrm{MW}$ when the temperature reaches $500^{\circ} \mathrm{C}$. In order to consider the impact of RVACS operation on the reactor natural circulation, a negative quasilinear heat flux was introduced to the vessel wall, which depends on the vessel wall temperature. With the exception of the vessel wall and lead free surface, all CFD model boundaries are considered as adiabatic. Table 3 gives the boundary conditions applied to the CFD model during steady state and transient conditions. The CFD model of SNRLFR-100 primary cooling system is shown in Figure 9. 
TABLE 3: CFD model boundary conditions.

\begin{tabular}{lcc}
\hline Sl. number & Boundary & Type \\
\hline 1 & core & $\begin{array}{c}\text { Heat source and } \\
\text { momentum sink } \\
\text { Heat sink and } \\
\text { momentum sink }\end{array}$ \\
3 & PHX & Negative heat flux \\
4 & Main vessel & Smooth conducting wall \\
5 & Heat barrier & Neglected \\
6 & Control plug & Smooth nonconducting \\
7 & Baffle representing & wall \\
\hline
\end{tabular}

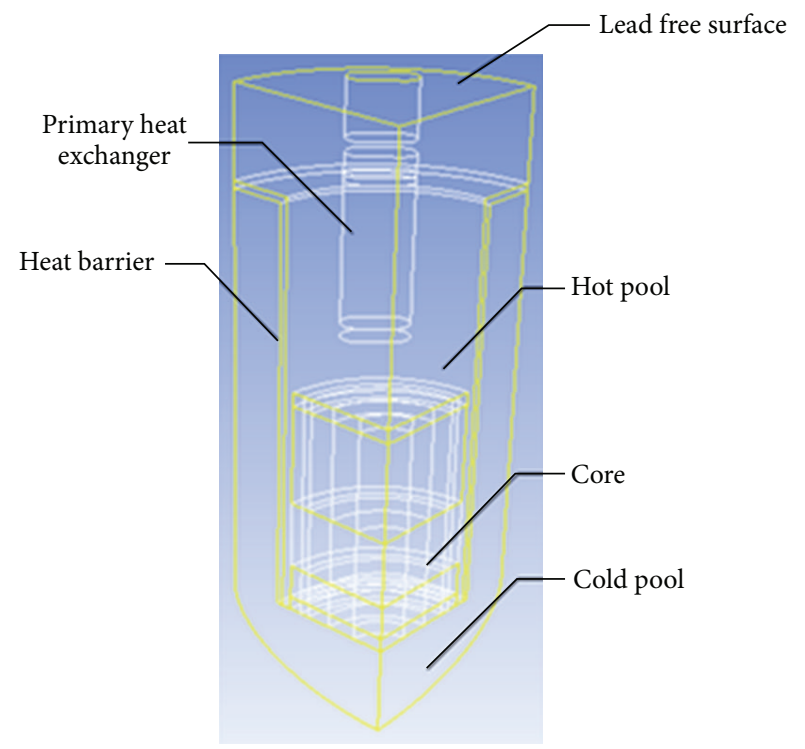

FIGURE 9: The 3D CFD model of SNRLFR-100 primary cooling system.

The natural circulation flow appears when large differences in temperature drive to large differences in the coolant density. Boussinesq approximation is commonly used in solving natural convection problem; it is suitable for very small temperature difference in the fluid. In this work, the CFD model utilized a user-defined equation of state model by specifying density as a function of temperature. This approach is considered to be less restrictive in terms of temperature gradient requirements and is able to capture simulated convection closer to actual conditions [19]. In order to obtain such a motion we have set all properties as a function of temperature. The temperature dependent lead properties correlations come from the lead or lead-alloy properties handbook edited by OECD/NEA (2007). The lead density is assumed to be a function of temperature as

$$
\rho\left[\mathrm{kg} * \mathrm{~m}^{-3}\right]=(11367-1.1944 \times T)
$$

for lead in the range of $600 \mathrm{~K}<T<1500 \mathrm{~K}$. The following correlation is used for viscosity $\mu$ :

$$
\mu[\mathrm{Pa} \cdot \mathrm{s}]=4.55 \times 10^{-4} e^{(1069 / T)} .
$$

For the mean coefficient of lead thermal expansion, we assume

$$
\begin{aligned}
\alpha_{v}\left[\mathrm{~m}^{3} * \mathrm{~K}^{-1}\right]= & 14.77 \times 10^{-6}+12.20 \\
& \times 10^{-9}(T-273.16) \\
& +12.18^{-12}(T-273.16) .
\end{aligned}
$$

The lead thermal conductivity $\lambda$ is

$$
\lambda\left[\mathrm{W} * \mathrm{~m}^{-1} * \mathrm{~K}^{-1}\right]=9.2+0.011
$$

The specific heat capacity at constant pressure for lead is assumed as

$$
\begin{aligned}
C_{p}\left[\mathrm{~J} * \mathrm{~kg}^{-1} * \mathrm{~K}^{-1}\right]= & 175.1-2.961 \times 10^{-2} \mathrm{~T}+1.985 \\
& \times 10^{-5} T^{2}-2.099 \times 10^{-9} T^{3} \\
& -1.524 \times 10^{6} T^{2} .
\end{aligned}
$$

For all simulations FLUENT 14.0 is used. Form the work in the framework of the ASCHLM project [20], in the present state-of-the-art of commercial CFD codes, the $k-\varepsilon$ RNG model not only has appeared as more convenient for liquid metal thermal-hydraulic analysis but also included a correction term that accounts for low-Reynolds number. Hence, the $k-\varepsilon$ RNG model was selected for turbulence modeling, and PISO pressure-velocity coupling scheme was used to conduct the steady state and transient simulations.

\section{Results and Discussion}

4.1. SNRLFR-100 Flow Characteristics at Nominal Condition. As mentioned before the reactor is operating at nominal conditions, which means thermal power production of $100 \mathrm{MW}$ and a coolant flow rate of $8528 \mathrm{~kg} / \mathrm{s}$. Using the previous CFD model, the steady state analysis has been carried out for the nominal conditions of SNRLFR-100. Figure 10 shows the velocity distribution of the SNRLFR-100 primary cooling system. From this figure, it can be seen that a stable natural circulation can be established in the primary cooling system. The maximum velocity of the core is $0.283 \mathrm{~m} / \mathrm{s}$ which located in the secondary fuel ring, and the maximum velocity of the whole primary cooling system occurs in PHX inlet region with the velocity about $0.583 \mathrm{~m} / \mathrm{s}$. On account of the corrosion and oxidation of the heavy liquid mental, the design limit of the maximum coolant velocity for SNRLFR100 is $2 \mathrm{~m} / \mathrm{s}$; from the velocity distribution, it can be seen that the maximum velocity of the coolant is lower than the design limit obviously. For the hot pool, the coolant flew upward and formed a large whirlpool finally, which will do much good for the coolant mixing. Above results show that the current thermal-hydraulic design is available, and the velocity distribution is acceptable.

For a natural circulation reactor, the driving force of the coolant is produced by the coolant density difference of the hot pool and cold pool of the reactor, which are core and heat exchanger, respectively. In the present CFD model that 


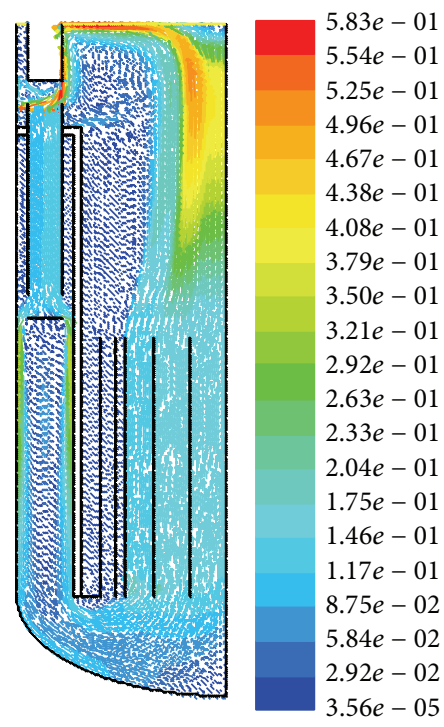

FIGURE 10: Velocity distribution of SNRLFR-100 primary cooling system.

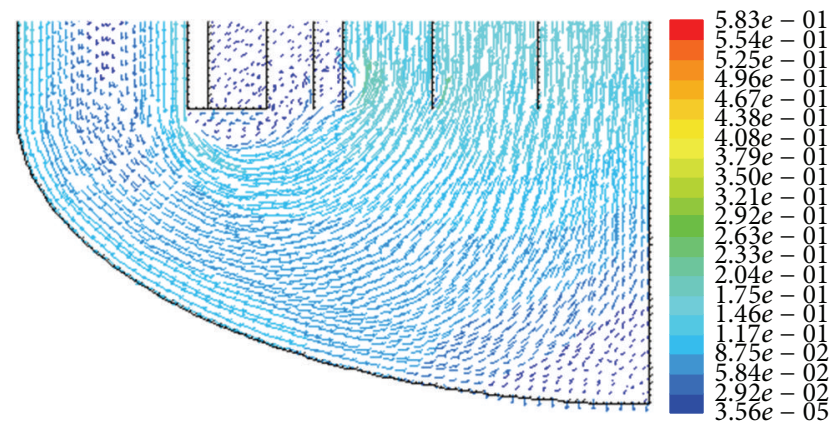

FIGURE 11: Velocity distribution of lower plenum bottom region.

we used, the core is divided into five rings; due to the lack of related shielding calculation at present stage, the power density of the reflector and shielding regions is equal to zero. The average power density of the three fuel rings that located at the inner core is different, which leads the corresponding driving force of each ring to be not identical. Figure 11 shows the velocity distribution of the cold plenum bottom region. For most of the reactor, the coolant mass flow rate of each assembly located at the core is distributed by the distribution device. Considering the fact that the coolant distribution device will increase the flow resistance, which will adversely affect the performance of natural circulation of SNRLFR100 , at present stage, the coolant distribution device has not been adopted in the current coolant distribution scheme; the current flow distribution design of SNRLFR-100 solely depends on the coolant automatic distribution; it is of great importance to study the features of the coolant distribution scheme of SNRLFR-100 during nominal state. Table 4 listed the coolant mass flow rate, the power share, and the mass flow share of each fuel ring. From Figure 11 and Table 4, it can be seen that the coolant is distributed automatically at the core inlet region. The maximum mass flow rate appears in
TABle 4: Mass flow rate, power distribution factor, and flow distribution factor of each fuel ring.

\begin{tabular}{lccc}
\hline Ring number Mass flow rate $(\mathrm{kg} / \mathrm{s})$ & Power share & Flow rate share \\
\hline Ring 1 & 1331.592 & 0.1498 & 0.1559 \\
Ring 2 & 3685.738 & 0.4368 & 0.4314 \\
Ring 3 & 3526.161 & 0.4134 & 0.4127 \\
\hline
\end{tabular}

the secondary fuel ring, which is also the maximum power ring. But the maximum flow rate share $\left(F_{m, \max }=0.4314\right)$ is smaller than the maximum power share $\left(F_{p, \max }=0.4314\right)$. The minimum mass flow rate appears in the first fuel ring, which is also the minimum power share ring. But the minimum flow rate share $\left(F_{m, \max }=0.4314\right)$ is larger than the minimum power share $\left(F_{p, \max }=0.1559\right)$.

The simulation results show that the mass flow rate of each fuel ring grows as the power increases, but the increase rate of mass flow rate is smaller than that of the power; it indicates that, solely relying on the natural circulation automatic distribution capacity, the coolant flow distribution cannot agree well with the power distribution in high power region; this phenomenon will result in local overheating of fuel rod; special attentions are needed to conduct further analysis of thermal mechanical features for fuel rod, especially in transient and accident conditions. Therefore, this phenomenon should be considered in the core mass flow distribution design for SNRLFR-100.

In order to fourthly assess the natural circulation capacity of the current mass flow distribution design, the hottest assembly of the core located at the third fuel ring was selected to analyze the thermal-hydraulic performance of the hottest assembly. Figure 12 shows the temperature distribution of the fuel rod of the hottest assembly. It can be seen that maximum center temperature and cladding temperature of the fuel rod are $925.9^{\circ} \mathrm{C}$ and $513.2^{\circ} \mathrm{C}$, respectively, which are far below the design limits. It indicates that the natural circulation flow automatic distribution capacity of SNRLFR-100 is sufficient, and the current core flow distribution design is acceptable.

4.2. SNRLFR-100 Temperature Distribution at Nominal Condition. Figure 13 presents the temperature distribution of SNRLFR-100 primary cooling system. From Figure 13, we can see that the coolant pool is divided into two regions obviously, namely, hot pool with relatively high temperature and cold pool with relatively cold temperature. The temperature distribution in the cold pool is more uniform than the hot pool, and the average coolant temperature of the cold pool is about $399.5^{\circ} \mathrm{C}$. For the hot pool, it can be seen that there exists obvious thermal stratification phenomenon above the core outlet region; this is mainly due to the coolant mixing in this region. On account of the fact that the average power density of each fuel ring is different, the coolant outlet temperature of each ring will be different accordingly, which can be seen clearly from Figure 11. From this figure, it also can be seen that the coolant outlet temperature of the secondary fuel ring is the highest one among those five core rings as its average power density is higher than any other core rings. In present study, due to the lack of related shielding calculation, the power 
TABLE 5: Difference between SNRLFR-100 design values and calculation results.

\begin{tabular}{lcc}
\hline Parameter & $\begin{array}{c}\text { Design } \\
\text { value }\left({ }^{\circ} \mathrm{C}\right)\end{array}$ & $\begin{array}{c}\text { Calculation } \\
\text { value }\left({ }^{\circ} \mathrm{C}\right)\end{array}$ \\
\hline Average temperature of PHX inlet & 479.1 & 479.5 \\
Average temperature of PHX outlet & 400.0 & 399.5 \\
Average temperature of hot pool & 479.1 & 479.5 \\
Average temperature of cold pool & 400.0 & 399.5 \\
Average temperature of core inlet & 400.0 & 399.5 \\
Average temperature of core outlet & 480.0 & 481.5 \\
\hline
\end{tabular}

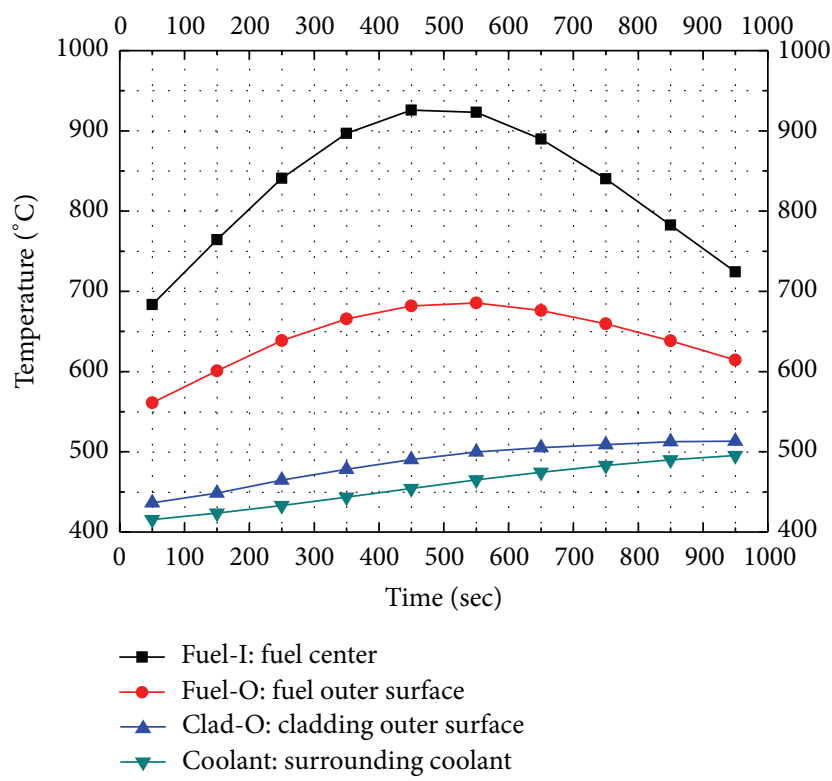

FIgURE 12: Temperature distribution of the fuel rod located at the core hottest fuel assembly.

density of the reflector and shielding regions is equal to zero. Considering the radial heat transfer of the core, the coolant in the reflector and shielding regions will be heated and the coolant temperature will increase; from the temperature distribution, it can be seen that obvious thermal stratification phenomena occur in these two regions along the axial direction. For the whole primary cooling system, the highest coolant temperature is about $764^{\circ} \mathrm{C}$ located in the secondary fuel ring, which is far below the corrosion limit $\left(550^{\circ} \mathrm{C}\right)$. The lowest temperature is about $400^{\circ} \mathrm{C}$, which is far above the melting temperature of lead $\left(327.5^{\circ} \mathrm{C}\right)$.

Table 5 gives the design temperature values of specific locations for primary cooling system which are compared with the calculated values. From the compared results, it can be seen that the temperature of the cold pool is slightly lower than the design value and the hot pool temperature is slightly higher than the design value; this is mainly due to the simplification of the adapted CFD model. The calculated results agree well with the design value, which indicates that the CFD simulation results are successful and current thermalhydraulic design of SNRLFR-100 is feasible.

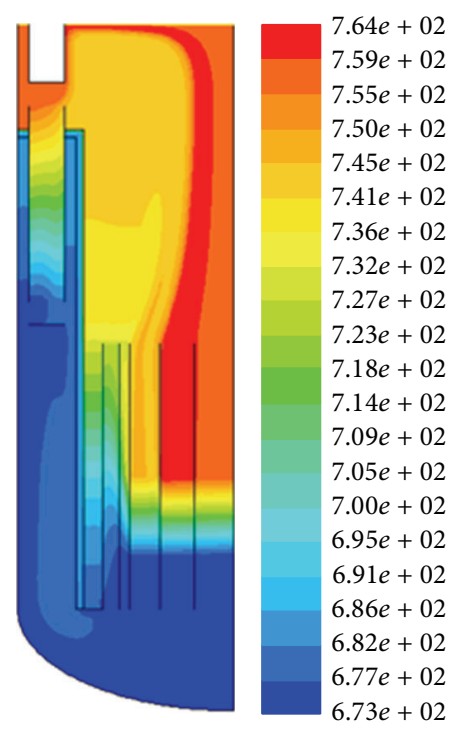

FIGURE 13: Temperature distribution of SNRLFR-100 primary cooling system (in K).

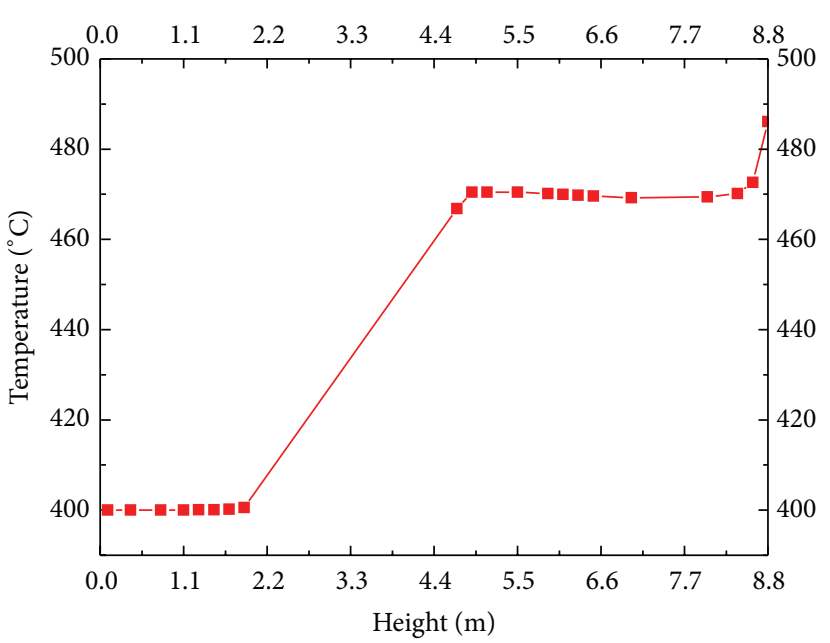

FIgURE 14: The axial coolant temperature distribution along the center of the reactor.

Figure 14 shows the axial coolant temperature distribution along the axis of the reactor. It can be seen that the average temperature change of different height in cold pool is very small. For the hot pool, the average temperature in most of the region is homogenous, and the temperature gradient can be ignored. From Figure 13, it can be seen that the coolant temperature increases rapidly from $8.4 \mathrm{~m}$ to the coolant free surface. This is mainly due to the lacking of above core structure in the present geometry design; the coolant mixing ability in the hot pool is limited; the coolant with relatively high temperature form the core flew upward along the mainstream and then deposited on the upper region of the hot pool as its density is relatively small. The thermal stratification on the upper part of the hot pool will bring additional thermal stress to the vessel wall and the internal structure of the reactor, which will do harm to the structural integrity of 


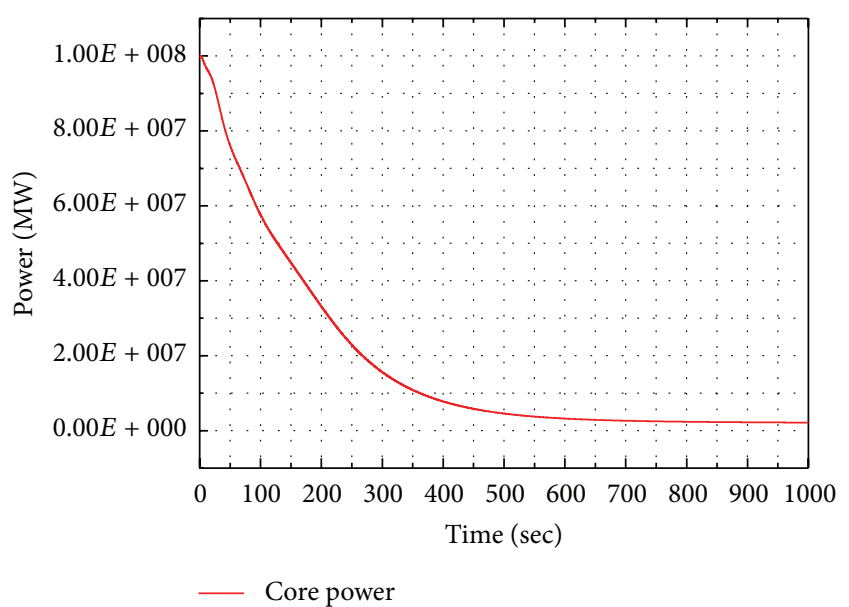

FIGURE 15: SNRLFR-100 core power as function of time during the ULOHS transient.

SNRLFR-100; special thermal stress analysis is needed in the future to study such phenomenon.

\section{Unprotected Loss of Heat Sink Transient (ULOHS)}

ULOHS is usually evaluated in the safety analysis for almost all types of reactors. The ULOHS at BOC has been conducted for SNCLFR-100. As there is no pump in the primary loop, pump trip will not occur. But the core could lose flow in another way. When the feed-water is lost due to the secondary pump trip and secondary loop pipe break, the heat removal and natural circulation capacity of the primary cooling system will decrease. That is to say, ULOHS will simultaneously lead to unprotected loss of flow (ULOF). The initial conditions of ULOHS for SNCLFR-100 were as follows. The reactor was at BOC with a full power operation of $100 \mathrm{MW}$ and nominal steady state operation. When the transient happened, all the secondary pumps failed and the secondary cooling system lost its function completely at this moment. Meanwhile, the decay heat removal systems were assumed to be unavailable too. During the whole transient process, no shutdown actions were taken. Based on the point kinetic model and fuel pin model, we can get the core power as a function of time, which can be considered as boundary condition for ULOHS simulation.

Figure 15 shows the core power as a function of time for SNRLFR-100; it can be seen that the core power decreases towards the decay level in about $1000 \mathrm{~s}$ transient and stabilizes about $3 \mathrm{MW}$. The main results of ULOHS transient analysis are illustrated in Figure 16.

From Figure 16(a), it can be seen that, in the first stage ( $0 \mathrm{~s} \sim 100 \mathrm{~s}$ ), the coolant temperature of the cold pool increases progressively after transient and the density difference between the hot pool and cold pool decreases quickly, which leads the natural driven force of the primary cooling system to decrease rapidly, and the coolant mass flow rate of the core decreases sharply when the accident happens. For the second stage (100s 200 s), the mass flow rate through the core tends to stabilize around $3450 \mathrm{~kg} / \mathrm{s}$; this may be due to the flow resistance of the whole primary system gradually decreasing as the mass flow rate reduced and achieves balance with the driving force in this short stage. In the third stage (200 s $1000 \mathrm{~s}$ ), the mass flow rate falls slowly and achieves a stable value as the driven force keeps decreasing.

As can be observed in Figure 16(b), with the reducing core power and loss of heat sink, the average coolant temperature in the core outlet region tends to stabilize around $504^{\circ} \mathrm{C}$. On account of the fact that the drop speed of the core power is higher than that of the core mass flow rate, the core outlet temperature increases sharply before $400 \mathrm{~s}$. The core outlet temperature is far below the lead boiling temperature; the coolant boiling phenomenon will not occur in the reactor.

From Figure 16(c), it can be seen that the maximum fuel temperature of the hottest pin under EOC conditions decreases from $925.9^{\circ} \mathrm{C}$ rapidly before $500 \mathrm{~s}$ and tends to stabilize around $536.5^{\circ} \mathrm{C}$, which was far below the design limit, $2300^{\circ} \mathrm{C}$. As shown in Figure $16(\mathrm{~d})$, the maximum cladding temperature of the hottest pin under EOC conditions increases fast before $100 \mathrm{~s}$ and reaches the peak value in $98 \mathrm{~s}$ with the temperature of $526^{\circ} \mathrm{C}$, which was also far below the design limit, $650^{\circ} \mathrm{C}$, under transient conditions.

Above analytical results show that SNCLFR-100 has good inherent performance; it could automatically shut itself down due to the negative feedback of the core during this whole transient. The maximum fuel temperature and cladding temperature were far below the design limit under transient conditions, which indicate that the current thermal-hydraulic design of SNRLFR-100 is acceptable. But, at the same time, we need to be aware that, for the long term, all temperatures increased slowly as the decay heat removal system failed; specific measures should be adapted to avoid the deterioration of the accident.

\section{Conclusions}

A 3D numerical simulation was conducted to study the natural circulation characteristics of SNRLFR-100 primary cooling system under nominal condition. The paper presents the analysis of velocity distribution, temperature distribution, and core flow distribution for a small modular natural circulation LFR SNRLFR-100. Moreover, in order to have a first evaluation of the system behavior in accident conditions, an unprotected loss of heat sink (ULOHS) transient simulation at BOC has been analyzed and discussed. The following conclusions are drawn from the present study:

(i) The stable natural circulation can be established in the primary cooling system; the maximum velocity is $0.583 \mathrm{~m} / \mathrm{s}$, which is far below the design limit. A large eddy is formed in the upper part of the hot pool, which is favorable for coolant mixing. The coolant can distribute automatically in the core inlet region, but the power share of each core fuel ring is inconsistent with its corresponding mass flow share; the maximum fuel temperature and cladding of the core hottest pin are far below the design limit with the current core flow distribution design, which means that 


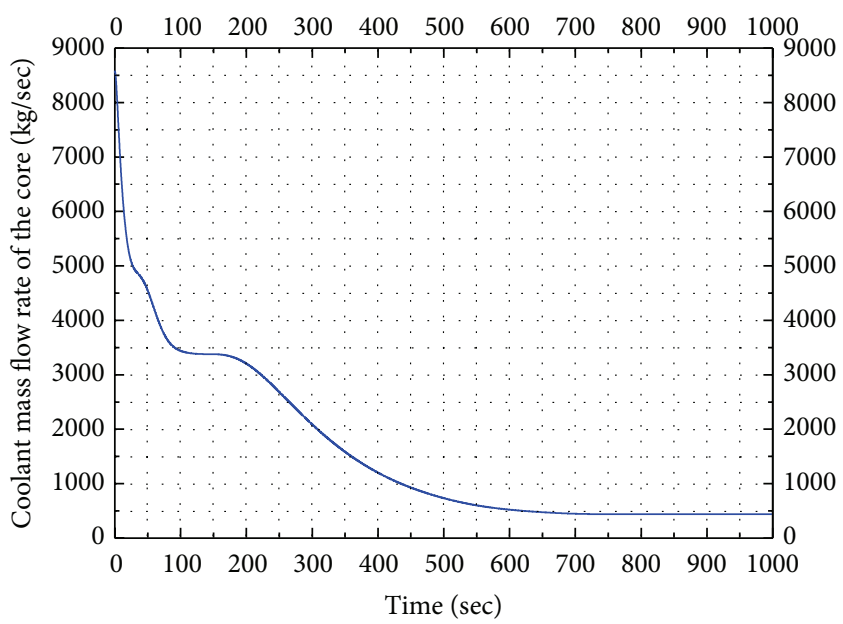

(a) Coolant mass flow rate of the core

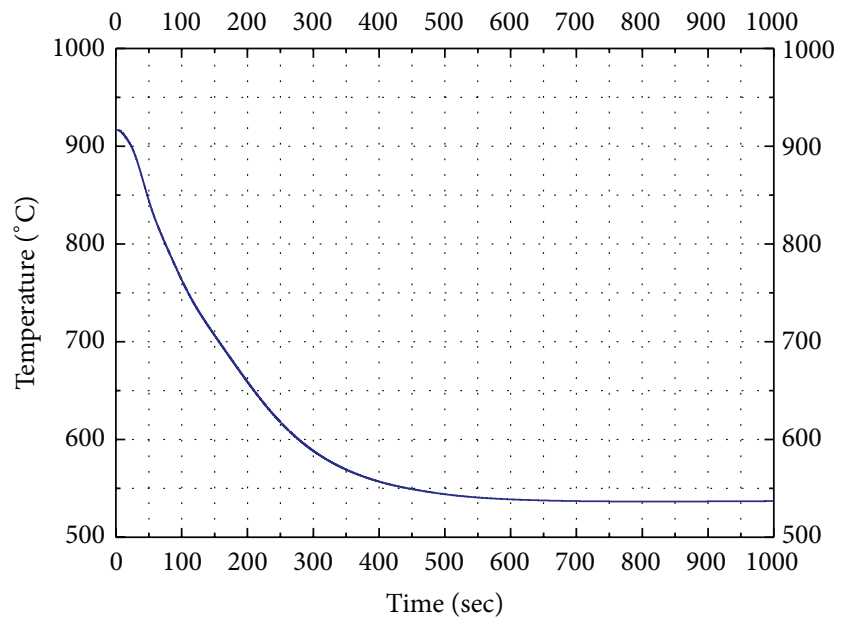

(c) Maximum fuel temperature of the hottest pin

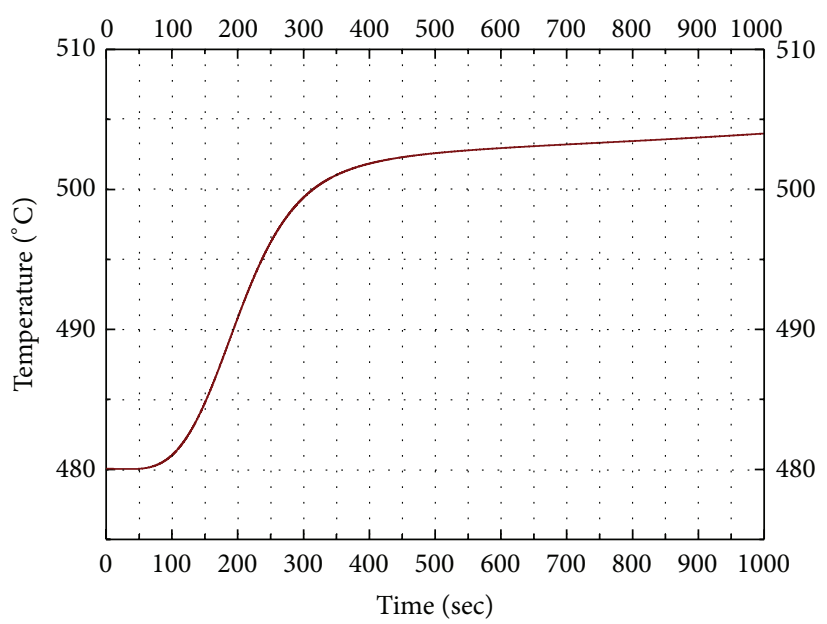

(b) Core outlet temperature

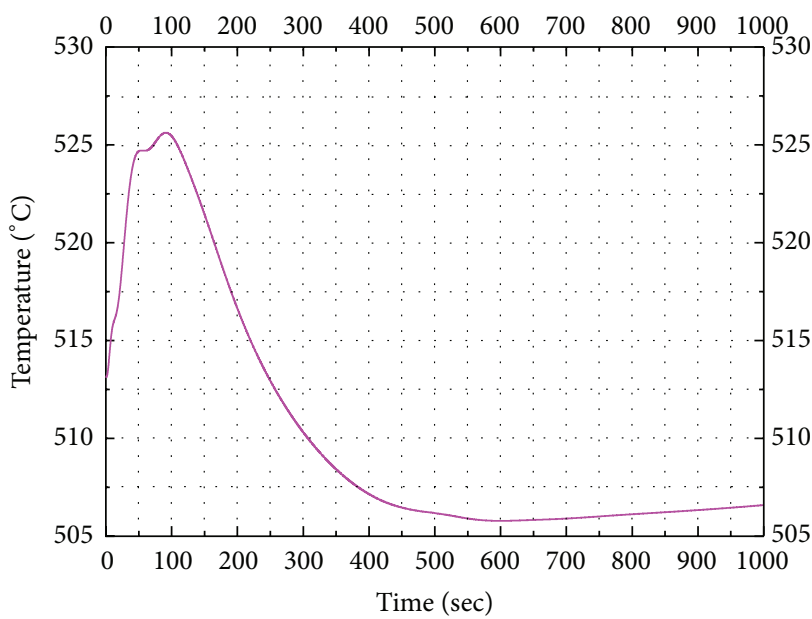

(d) Maximum cladding temperature of the hottest pin

FIGURE 16: Results for ULOHS transient for SNRLFR-100.

the current flow distribution scheme is feasible, but detailed core flow distribution study is still needed for further analysis.

(ii) The temperature distribution of primary circuit shows that the coolant pool is divided into two regions obviously, namely, hot pool and cold pool, and the temperature distribution of the cold pool is almost uniform, while obvious thermal stratification existed in the hot pool. The maximum and minimum temperatures of the primary circuit are well between the solidification limit and corrosion limit. The coolant average temperature increases sharply in the upper part of hot pool, which may bring additional thermal stress to the vessel wall and internal structure of the reactor; special attention should be added to conduct further analysis in the future.

(iii) The simulation results under nominal condition show that the current thermal-hydraulic design scheme is acceptable and reasonable. The analysis results of ULOHS simulation at BOC show that the reactor has a good inherent safety characteristic; the maximum fuel temperature and cladding temperature are far below the design limit; coolant boiling, cladding failure, and local fuel melting did not take place after transient in short term, which is far below the design limit at accident condition. But for the long term, all temperatures increase slowly as the decay heat removal system failed; specific measures should be adapted to avoid the deterioration of the accident.

Above simulation results have shown that the small modular natural circulation LFR has a lot of prominent advantages; simplified geometry design and excellent inherent performance give it a good prospect for development. Meanwhile, the coupling of system code and CFD code to study the complicated thermal-hydraulic phenomena that occur in the typical pool type reactor and increasing the calculation speed at the same time are required in the future work. As the computational resource is limited, the coupling method can improve the simulation accuracy as the unnecessary simplifications and assumptions can be omitted, and more steady 
and transient cases can be simulated due to smaller simulation time and computational resources are demanded. The coupling of the classical system code and commercial CFD code is our future work, which will be used to have a more comprehensive natural circulation analysis for SNRLFR.

\section{Conflict of Interests}

The authors declare that there is no conflict of interests regarding the publication of this paper.

\section{References}

[1] IAEA, "Liquid metal coolants for fast reactors cooled by sodium, lead, and lead-bismuth eutectic," Tech. Rep. NP-T-1.6, IAEA, 2012.

[2] H. A. Abderrahim, P. Kupschus, E. Malambu et al., "MYRRHA: a multipurpose accelerator driven system for research \& development," Nuclear Instruments and Methods in Physics Research Section A: Accelerators, Spectrometers, Detectors and Associated Equipment, vol. 463, no. 3, pp. 487-494, 2001.

[3] T. W. Kim, K. B. Park, K. H. Jeong, G. M. Lee, and S. Choi, "Dynamic characteristics of the integral reactor SMART," Journal of the Korean Nuclear Society, vol. 33, no. 1, pp. 111-120, 2001.

[4] X. Cheng, J. E. Cahalan, and P. J. Finck, "Safety analysis of an accelerator-driven test facility," Nuclear Engineering and Design, vol. 229, no. 2-3, pp. 289-306, 2004.

[5] J. J. Sienicki, Status Report on the Small Secure Transportable Autonomous Reactor (SSTAR)/Lead-Cooled Fast Reactor (LFR) and Supporting Research and Development, Argonne National Laboratory, Lemont, Ill, USA, 2006.

[6] C. F. Smith, W. G. Halsey, N. W. Brown, J. J. Sienicki, A. Moisseytsev, and D. C. Wade, "SSTAR: the US lead-cooled fast reactor (LFR)," Journal of Nuclear Materials, vol. 376, no. 3, pp. 255-259, 2008.

[7] C. Rubbia, J. A. Rubio, S. Buono et al., "Conceptual design of a fast neutron operated high power energy amplifier," Tech. Rep. CERN/AT/95-44 (ET), 1995.

[8] Y. Shin, S. Choi, J. Cho, J. H. Kim, and I. S. Hwang, "Advanced passive design of small modular reactor cooled by heavy liquid metal natural circulation," Progress in Nuclear Energy, vol. 83, pp. 433-442, 2015.

[9] H. Chen, Z. Chen, T. Zhou, M. Jin, Y. Bai, and W. Wang, "Preliminary thermal-hydraulic design and analysis of china lead alloy cooled research reactor (CLEAR-I)," in Proceedings of the 9th International Topical Meeting on Nuclear Thermal-Hydraulics, Operation and Safety (NUTHOS-9 '12), pp. 1-9, Kaohsiung, Taiwan, September 2012.

[10] Z. Chen, P. Zhao, G. Zhou, and H. Chen, "Study of core flow distribution for small modular natural circulation lead or leadalloy cooled fast reactors," Annals of Nuclear Energy, vol. 72, pp. 76-83, 2014.

[11] Z. Chen, G. Zhou, P. Zhao, and H. Chen, "Development and application of a thermal-hydraulics analysis code for small modular natural circulation lead or lead-alloy cooled fast reactors," Annals of Nuclear Energy, vol. 73, pp. 68-74, 2014.

[12] X. Cheng, A. Batta, G. Bandini et al., "European activities on crosscutting thermal-hydraulic phenomena for innovative nuclear systems," Nuclear Engineering and Design, vol. 290, pp. $2-12,2015$.
[13] Z. Chen, X.-N. Chen, A. Rineiski, P. Zhao, and H. Chen, "Coupling a CFD code with neutron kinetics and pin thermal models for nuclear reactor safety analyses," Annals of Nuclear Energy, vol. 83, pp. 41-49, 2015.

[14] M. Vanderhaegen, J. Vierendeels, and B. Arien, "CFD analysis of the MYRRHA primary cooling system," Nuclear Engineering and Design, vol. 241, no. 3, pp. 775-784, 2011.

[15] A. Abánades and A. Peña, "Steady-state natural circulation analysis with computational fluid dynamic codes of a liquid metal-cooled accelerator driven system," Nuclear Engineering and Design, vol. 239, no. 2, pp. 418-424, 2009.

[16] H. Huang and J. Ayoub, "Applicability of the Forchheimer equation for non-Darcy flow in porous media," SPE Journal, vol. 13, no. 1, pp. 112-122, 2008.

[17] N. E. Todreas and M. S. Kazimi, Nuclear Systems II-Elements of Thermal Hydraulic Design, Hemisphere Publishing Corporation, 2001.

[18] K. Rehme, "Pressure drop correlations for fuel element spacers," Nuclear Technology, vol. 17, no. 1, pp. 15-23, 1973.

[19] S. Sipaun and S. Usman, "Prediction of Missouri S\&T Reactor's natural convection with porous media approximation," Nuclear Engineering and Design, vol. 285, pp. 241-248, 2015.

[20] B. Arien, "Assessment of computational fluid dynamics codes for heavy liquid metals," Final Report FIKW-CT-2001-80121, ASCHLIM, 2003. 

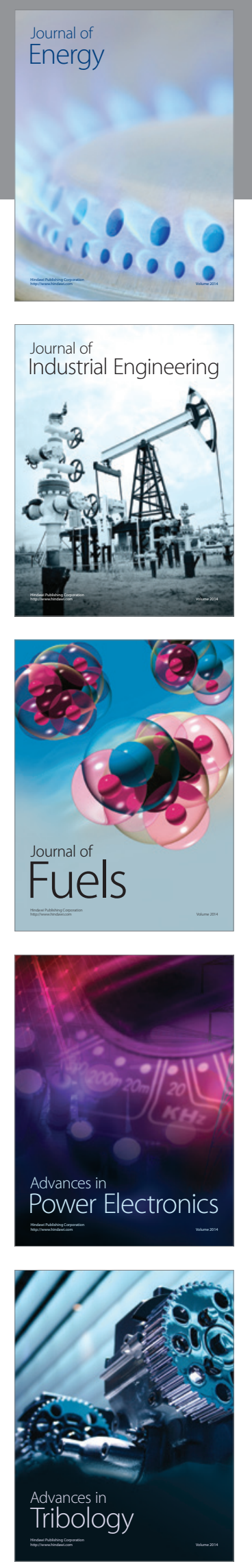
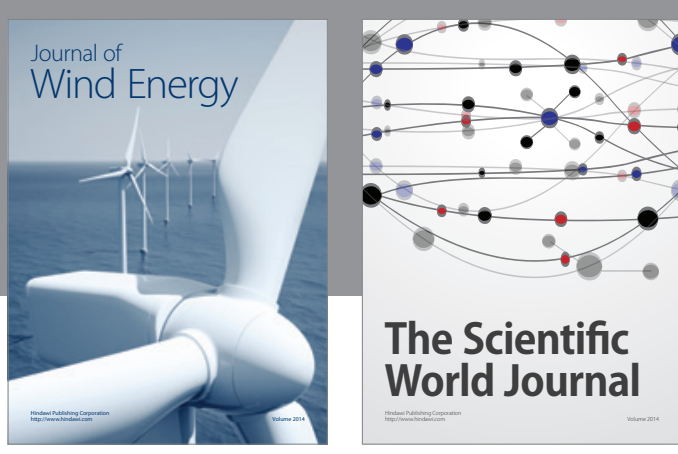

The Scientific World Journal
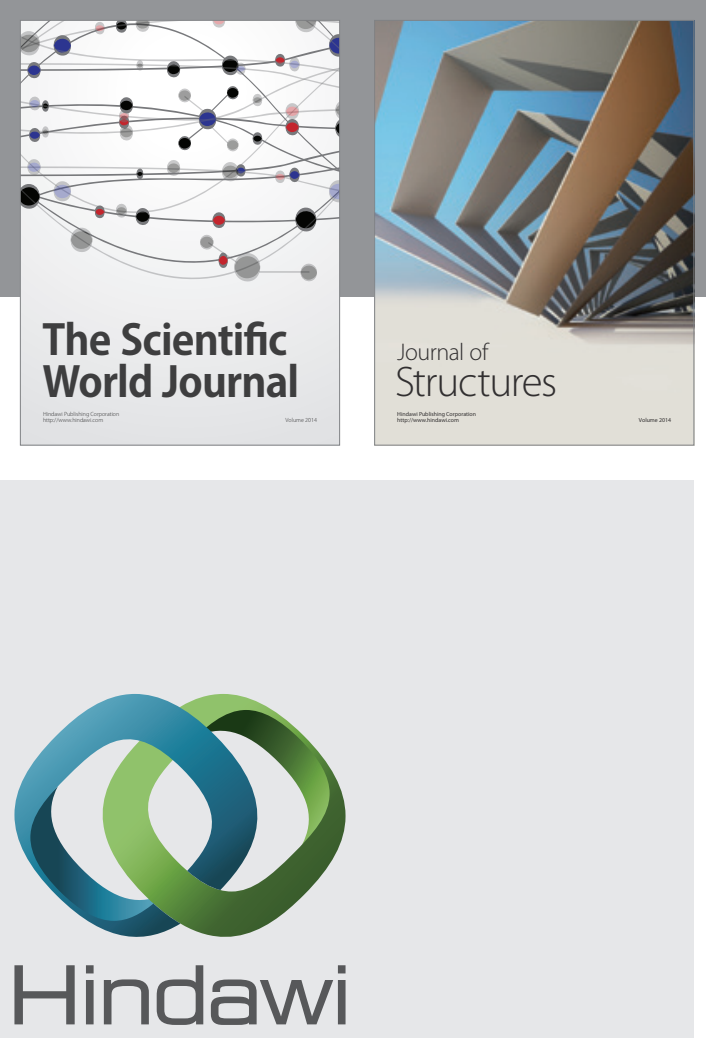

Submit your manuscripts at

http://www.hindawi.com
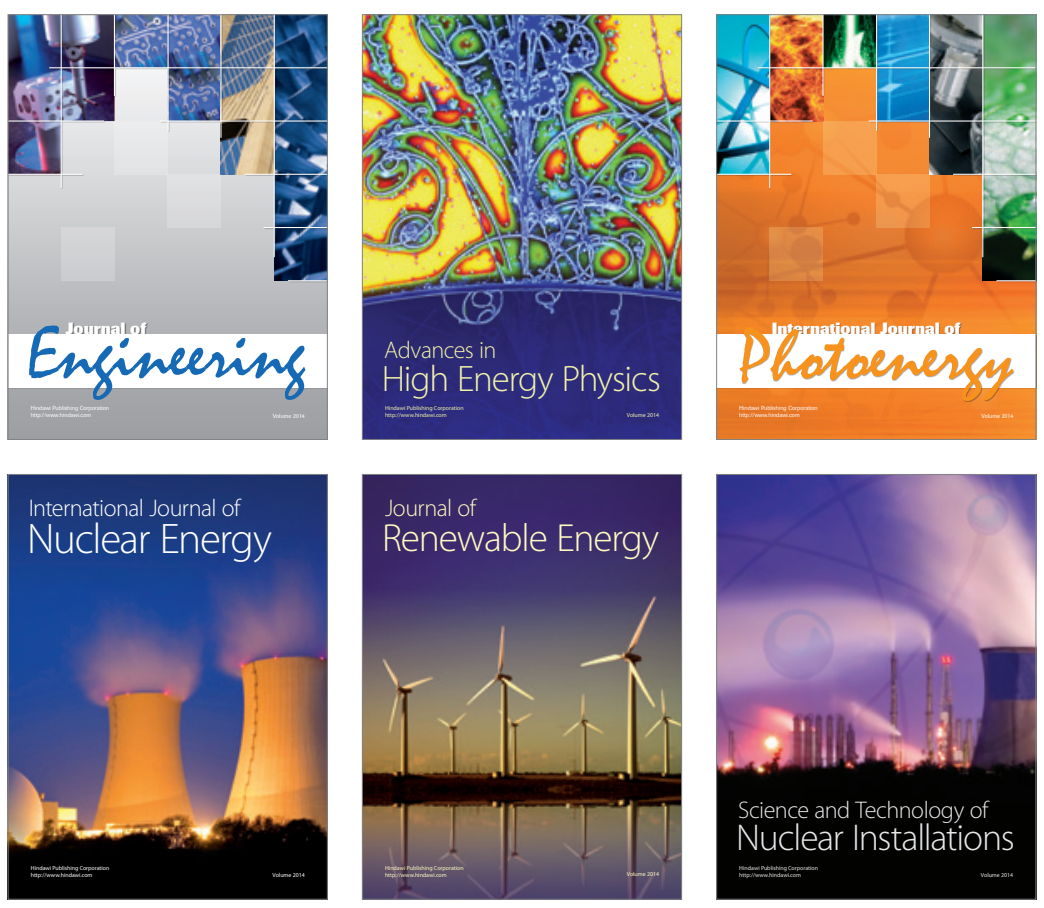
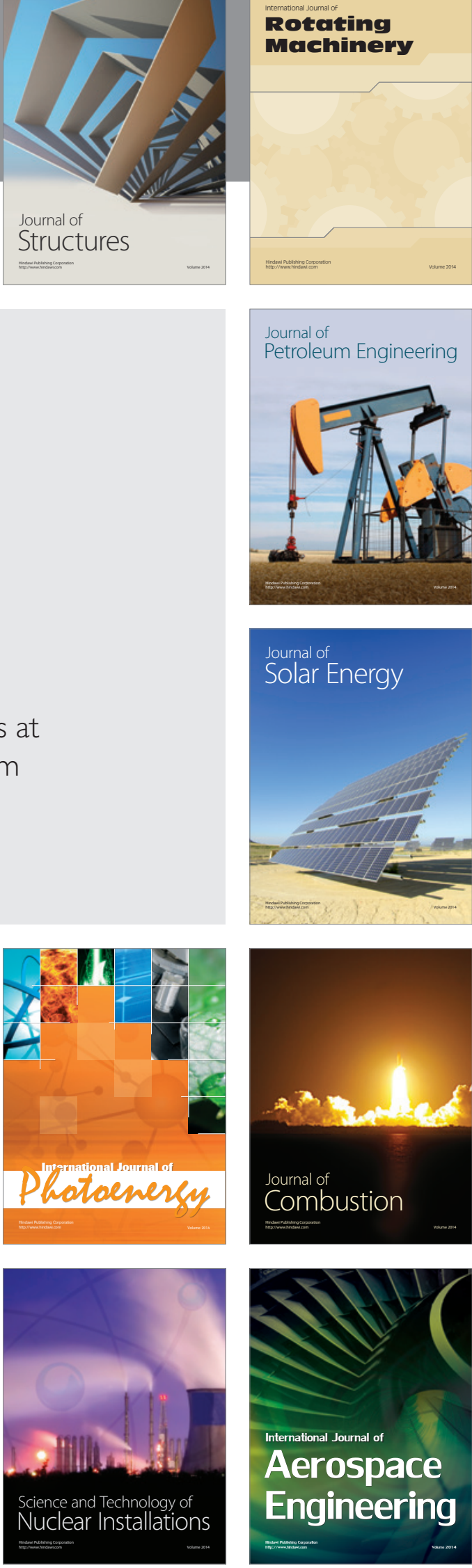